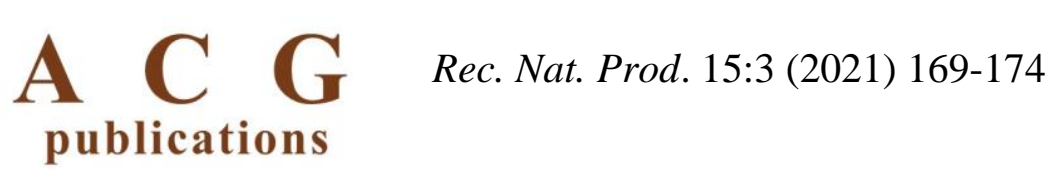

records of natural products

\title{
Antiradical Aromatic Constituents from Pleurotus eryngii
}

\author{
Xin-Xin Cao $\oplus^{1}$, Jin-Yue Sun $\oplus^{2}$, Chao Liu $\odot^{2}$, Jun-Sheng Zhang $\oplus^{1 *}$ and \\ Hua Zhang ${ }^{1^{*}}$

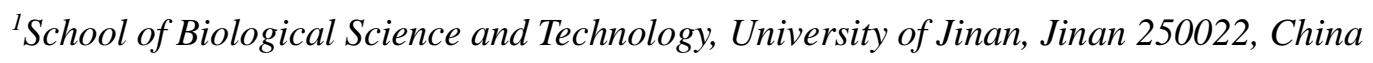 \\ ${ }^{2}$ Institute of Agro-Food Science and Technology, Shandong Academy of Agricultural Sciences, Jinan \\ 250100, China
}

(Received August 31, 2020; Revised September 28, 2020; Accepted October 01, 2020)

\begin{abstract}
Six aromatic compounds including a new (Z)-ferulic acid ester (1) and a new syringic acid ester (2), as well as four known ferulic acid esters (3-6), were isolated from a well-known edible mushroom, Pleurotus eryngii. Structures of these aromatics were unambiguously characterized via spectroscopic methods especially MS and NMR techniques. All the isolates were assessed for their antiradical effect and NO production inhibitory activity in RAW264.7 macrophages, and compounds $\mathbf{1}$ and $\mathbf{3}$ displayed mild DPPH radical removing activity, with $\mathrm{IC}_{50}$ values of 25.0 and $21.6 \mu \mathrm{M}$, respectively.
\end{abstract}

Keywords: Pleurotus eryngii; aromatics; ferulic acid ester; syringic acid ester; antiradical. (C) 2020 ACG Publications. All rights reserved.

\section{Introduction}

The king oyster mushroom (Pleurotus eryngii) is a well-known edible macro mushroom cultivated all over the world and has been reported to possess various pharmacological benefits to human health [1]. The bioactive constituents of $P$. eryngii have been intensively investigated in recent years. The macromolecule ingredients from this mushroom mainly include proteins [2,3] and polysaccharides [4], and great efforts have been particularly devoted to the study of polysaccharides due to their diverse bioactivities such as antitumor and immunomodulatory activities [4]. In addition to the macromolecules, small molecule natural products have also attracted attentions from the scientific community. Steroids are so far the mostly reported compounds and they show potential NO production and aromatase inhibitory effect [5-9]. Moreover, cytotoxic [10,11], anti-osteoporotic [12], NQO1 induction [13], antioxidant [14] and anti-inflammatory [11] phenolic constituents have also been reported. Other minor constituents [15] comprise cytotoxic triterpenoids [16] and diterpenoids [17], as well as sesquiterpenoids [13,18] and monoterpenoids [19].

As a project to explore the further economic and pharmacological values of bulk edible mushrooms in Shandong province, we have chosen P. eryngii as one of our research subjects and carried out an intensive chemical study into the small molecule constituents. As a result, an array of aromatic compounds, including five ferulic acid esters (1 and 3-6) and a syringic acid ester (2), have been obtained and structurally characterized, and the structures of $\mathbf{1}$ and $\mathbf{2}$ have been reported for the first time. Our bioassays established that the (Z)-ferulic acid esters $\mathbf{1}$ and $\mathbf{3}$ exhibited comparable antiradical activity as the positive control ascorbic acid. The isolation, structure identification and biological assessment of the aromatic compounds are thus depicted below.

\footnotetext{
*Corresponding authors: E-Mail: bio_zhangjs@ujn.edu.cn and bio_zhangh@ujn.edu.cn 
<smiles>CCCCCOC(=O)/C=C\c1ccc(O)c(OC)c1</smiles><smiles>CCCCOC(=O)/C=C/c1ccc(O)c(OC)c1</smiles><smiles>CC/C=C\C[C]OC(=O)c1cc(OC)c(O)c(OC)c1</smiles>

2<smiles>CCCOC(=O)/C=C/c1ccc(O)c(OC)c1</smiles><smiles>COC(=O)/C=C\c1ccc(O)c(OC)c1</smiles>

3<smiles>COC(=O)/C=C/c1ccc(O)c(OC)c1</smiles>

Figure 1. Structures of aromatic compounds from P. eryngii

\section{Materials and Methods}

\subsection{General}

NMR spectra were acquired from a Bruker Avance DRX600 spectrometer (Bruker BioSpin AG, Fällanden, Switzerland) and the residual solvent peaks $\left(\mathrm{CDCl}_{3} \delta_{\mathrm{H}} 7.26, \delta_{\mathrm{C}} 77.16\right)$ were used as references. HR-MS analyses were performed on Agilent 6545 Q-TOF MS spectrometer (Agilent Technologies Inc., Waldbronn, Germany) with separate ESI and APCI ion source. The HPLC analyses/separations were carried out on a Shimadzu 20A series LC instrument (Shimadzu, Tokyo, Japan) coupled with a YMC-Pack ODS-A column $(5 \mu \mathrm{m}, 10 \times 250 \mathrm{~mm}$, YMC Co. Ltd., Tokyo, Japan). D101-macroporous absorption resin (Sinopharm Chemical Reagent Co. Ltd., Shanghai, China), Sephadex LH-20 gel (GE Healthcare Bio-Sciences AB, Uppsala, Sweden), reversed phase (RP) $\mathrm{C}_{18}$ silica gel (Merck KGaA, Darmstadt, Germany) and silica gel (300-400 mesh, Qingdao Marine Chemical Co. Ltd., Qingdao, China) were mainly used for column chromatography (CC). Analytical grade solvents (Tianjin Fuyu Fine Chemical Co. Ltd., Tianjin, China) were used for CC, and chromatographic grade solvents (Oceanpak Alexative Chemical Ltd., Goteborg, Sweden) were used for HPLC.

\subsection{Fungal Material}

The fresh fungal materials of Pleurotus eryngii were bought in May 2019 from the market of Jinan city and were identified by Prof. Guo-hua Ye of Shandong College of Traditional Chinese Medicine. The voucher specimen of the fungus has been deposited at the corresponding author's institution with an access number of npmc-056.

\subsection{Extraction and Isolation}

The dried fruiting bodies of $P$. eryngii $(10.0 \mathrm{~kg})$ were chopped into pieces and then dipped in $95 \% \mathrm{EtOH}$ at r.t. for three times (once a week). The EtOH extraction $(700 \mathrm{~g}$ ) was combined and evaporated in vacuum to give a brown residue, which was then partitioned between EtOAc $(1.0 \mathrm{~L} \times 3)$ and water $(1.5 \mathrm{~L})$. The EtOAc layer was combined with solvent being removed in vacuo to afford the EtOAc partition $(260 \mathrm{~g})$. The EtOAc part was fractionated by D-101 macroporous resin CC (EtOH$\mathrm{H}_{2} \mathrm{O}, 30 \%, 50 \%, 70 \%$ and $\left.95 \%\right)$ to obtain four elutions. The $70 \%$ ethanol elution $(56 \mathrm{~g})$ was fractionated via silica gel CC using petroleum ether (PE)-EtOAc (99:1 to 80:20) to afford eight fractions (Frs. 1-8). Fr. 5 was subject to a RP-18 column (70\% to $100 \% \mathrm{MeOH}-\mathrm{H}_{2} \mathrm{O}$ ) to obtain five sub-fractions (Frs. 5A-5J), and Fr. 5A was further purified by semi-preparative HPLC $(3.00 \mathrm{~mL} / \mathrm{min}$, $\left.85 \% \mathrm{MeCN}-\mathrm{H}_{2} \mathrm{O}\right)$ to yield $3\left(1.2 \mathrm{mg}, t_{\mathrm{R}}=18.2 \mathrm{~min}\right)$. Fr. 5B was chromatographed on RP-18 CC again, with $60 \%$ to $100 \% \mathrm{MeOH}-\mathrm{H}_{2} \mathrm{O}$ as eluent, to afford two sub-fractions, and the second one was purified

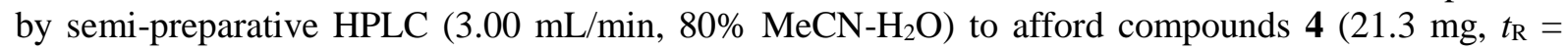


$29.0 \mathrm{~min}), \mathbf{5}\left(37.0 \mathrm{mg}, t_{\mathrm{R}}=28.0 \mathrm{~min}\right)$ and $\mathbf{6}\left(30.7 \mathrm{mg}, t_{\mathrm{R}}=17.0 \mathrm{~min}\right)$. Fr. 6 was separated by Sephadex LH-20 CC (in 1:1 $\mathrm{CH}_{2} \mathrm{Cl}_{2}-\mathrm{MeOH}$ ) to return six fractions (Frs. 6A-6F), and Fr. 6F was then subject to RP-18 CC (70\% to $\left.100 \% \mathrm{MeOH}-\mathrm{H}_{2} \mathrm{O}\right)$ to afford four sub-fractions (Frs. 6A1-6A4). Fraction 6A2 was first separated by silica gel $\mathrm{CC}$ using $\mathrm{CH}_{2} \mathrm{Cl}_{2}-\mathrm{MeOH}$ as eluent (200:1 to 60:1) and then purified by

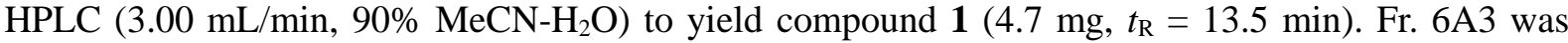
first submitted to Sephadex LH-20 CC (in 1:1 $\mathrm{CH}_{2} \mathrm{Cl}_{2}-\mathrm{MeOH}$ ) and then purified by semi-preparative $\mathrm{HPLC}\left(3.00 \mathrm{~mL} / \mathrm{min}, 90 \% \mathrm{MeCN}-\mathrm{H}_{2} \mathrm{O}\right)$ to yield compound $2\left(2.5 \mathrm{mg}, t_{\mathrm{R}}=16.0 \mathrm{~min}\right)$.

Compound 1: Colorless gum; UV (MeOH) $\lambda_{\max }(\log \varepsilon) 307(4.48) ;{ }^{1} \mathrm{H}$ and ${ }^{13} \mathrm{C}$ NMR data $\left(\mathrm{CDCl}_{3}\right)$ see Table 1; (+)-HR-ESIMS $m / z 265.1432[\mathrm{M}+\mathrm{H}]^{+}\left(\right.$calcd for $\left.\mathrm{C}_{15} \mathrm{H}_{21} \mathrm{O}_{4}{ }^{+}, 265.1434\right)$.

Compound 2: Colorless gum; UV (MeOH) $\lambda_{\max }(\log \varepsilon) 275(4.45) ;{ }^{1} \mathrm{H}$ and ${ }^{13} \mathrm{C}$ NMR data $\left(\mathrm{CDCl}_{3}\right)$ see Table 1; (+)-HR-APCIMS m/z 281.1388 [M + H] ${ }^{+}$(calcd for $\mathrm{C}_{15} \mathrm{H}_{21} \mathrm{O}_{5}{ }^{+}, 281.1384$ ).

\subsection{Bioassays}

\subsubsection{DPPH Radical Scavenging Aactivity}

The antioxidant property of all these compounds was assessed by the DPPH radical removing assay as we described previously [20-22] with ascorbic acid as the positive control.

\subsubsection{NO Production Inhibitory Assay}

The nitric oxide (NO) production inhibitory capability of these aromatics was assessed in a lipopolysaccharide (LPS)-induced murine RAW264.7 macrophage model as we described formerly [23].

\section{Results and Discussion}

Compound 1 was isolated as a colorless gum, with the molecular formula of $\mathrm{C}_{15} \mathrm{H}_{20} \mathrm{O}_{4}$ as determined by the (+)-HR-ESIMS analysis at $\mathrm{m} / \mathrm{z} 265.1432$ (calcd for $[\mathrm{M}+\mathrm{H}]^{+}, 265.1434$ ). Apart from the resonances $\left[\delta_{\mathrm{H}} 7.76(\mathrm{~d}, J=1.9 \mathrm{~Hz}), 7.10(\mathrm{dd}, J=8.1,1.9 \mathrm{~Hz}), 6.90(\mathrm{~d}, J=8.1 \mathrm{~Hz}) ; 6.79,5.82\right.$ (both d, $J=12.8 \mathrm{~Hz}) ; 5.83(\mathrm{~s}, \mathrm{OH}) ; 3.93(\mathrm{~s}, 3 \mathrm{H})$ ] observed for a $Z$-feruloyl unit as in methyl (Z)-ferulic acid ester (3) [22], the ${ }^{1} \mathrm{H}$ NMR data (Table 1) for $\mathbf{1}$ also revealed the existence of an amyloxy group at $\delta_{\mathrm{H}} 4.12(\mathrm{t}, J=6.8 \mathrm{~Hz}, 2 \mathrm{H}), 1.65(\mathrm{~m}, 2 \mathrm{H}), 1.33(\mathrm{~m}, 4 \mathrm{H})$ and $0.90(\mathrm{t}, J=6.8 \mathrm{~Hz}, 3 \mathrm{H})$. Analysis of the ${ }^{13} \mathrm{C}$ NMR data (Table 1) also confirmed the aforementioned assignments with typical signals for the $Z$ feruloyl and amyloxy fragments, and the two fragments were connected via an ester bond as evidenced by the chemical shift of $\mathrm{H}_{2}-1^{\prime}\left(\delta_{\mathrm{H}} 4.12\right.$ ) and its $\mathrm{HMBC}$ correlation (Fig. 2) to C-9 ( $\delta_{\mathrm{C}} 166.8$ ). Compound 1 was thus elucidated to be amyl $(Z)$-ferulic acid ester.
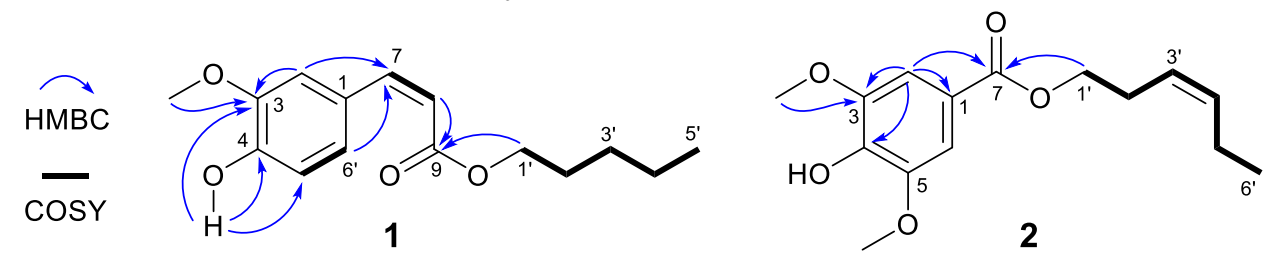

Figure 2. ${ }^{1} \mathrm{H}-{ }^{1} \mathrm{H}$ COSY and selected $\mathrm{HMBC}$ correlations for $\mathbf{1}$ and $\mathbf{2}$

Compound 2 was obtained as a colorless gum with the molecular formula of $\mathrm{C}_{15} \mathrm{H}_{20} \mathrm{O}_{5}$ as deduced from the (+)-HR-APCIMS ion at $m / z 281.1388$ (calcd for $[\mathrm{M}+\mathrm{H}]^{+}, 281.1384$ ). Examination of the NMR data (Table 1) for 2 established the existence of a syringoyl residue at $\delta_{\mathrm{H}} 7.32(\mathrm{~s}, 2 \mathrm{H})$ and $\delta_{\mathrm{C}} 166.5,146.7(2 \mathrm{C}), 139.3,121.5,106.7(2 \mathrm{C})$, as well as the existence of a (Z)-3-hexenyloxy unit at $\delta_{\mathrm{H}} 5.54(\mathrm{dtt}, J=10.7,7.3,1.5 \mathrm{~Hz}), 5.40(\mathrm{dtt}, J=10.7,7.0,1.5 \mathrm{~Hz}), 4.30(\mathrm{t}, J=6.9 \mathrm{~Hz}, 2 \mathrm{H}), 2.52(\mathrm{~m}$, $2 \mathrm{H}), 2.10(\mathrm{~m}, 2 \mathrm{H}), 0.97(\mathrm{t}, J=7.5 \mathrm{~Hz})$, and $\delta_{\mathrm{C}} 134.8,123.9,64.6,27.1,20.8,14.4$. Further 
interpretation of 2D NMR data (Fig. 2) corroborated the aforementioned assignments, revealing key ${ }^{1} \mathrm{H}-{ }^{1} \mathrm{H}$ COSY fragments of $\mathrm{H}_{2}-1$ ' to $\mathrm{H}_{3}-6$ ' and $\mathrm{HMBC}$ correlations from $\mathrm{H}-2(6)$ to $\mathrm{C}-1, \mathrm{C}-3(5), \mathrm{C}-4$ and C-7. Finally, the two structural fragments were linked via an ester bond as demonstrated by the chemical shift of $\mathrm{H}_{2}-1^{\prime}\left(\delta_{\mathrm{H}} 4.30\right)$ and its HMBC correlation (Fig. 2) to C-7 ( $\delta_{\mathrm{C}} 166.5$ ). Compound 2 was thus characterized to be $(Z)$-3-hexenyl syringic acid ester.

Table 1. NMR Data of compounds $\mathbf{1}$ and $\mathbf{2}$ in $\mathrm{CDCl}_{3}$

\begin{tabular}{|c|c|c|c|c|}
\hline \multirow{3}{*}{ No } & \multicolumn{2}{|r|}{1} & \multicolumn{2}{|r|}{2} \\
\hline & \multicolumn{2}{|r|}{1} & \multicolumn{2}{|r|}{2} \\
\hline & $\boldsymbol{\delta}_{\mathrm{C}}$ & $\boldsymbol{\delta}_{\mathrm{H}}$ & $\boldsymbol{\delta}_{\mathrm{C}}$ & $\boldsymbol{\delta}_{\mathrm{H}}$ \\
\hline 1 & 127.4 & & 121.5 & \\
\hline 2 & 112.9 & 7.76, d (1.9) & 106.7 & $7.32, \mathrm{~s}$ \\
\hline 3 & 146.0 & & 146.7 & \\
\hline 4 & 147.1 & & 139.3 & \\
\hline 5 & 113.9 & $6.90, \mathrm{~d}(8.1)$ & 146.7 & \\
\hline 6 & 125.7 & $7.10, \mathrm{dd}(8.1,1.9)$ & 106.7 & $7.32, \mathrm{~s}$ \\
\hline 7 & 143.7 & $6.79, \mathrm{~d}(12.8)$ & 166.5 & \\
\hline 8 & 117.1 & $5.82, \mathrm{~d}(12.8)$ & & \\
\hline 9 & 166.8 & & & \\
\hline $1^{\prime}$ & 64.6 & $4.12, \mathrm{t}(6.8)$ & 64.6 & $4.30, \mathrm{t}(6.9)$ \\
\hline $2^{\prime}$ & 28.5 & $1.65, \mathrm{~m}$ & 27.1 & $2.52, \mathrm{~m}$ \\
\hline $3^{\prime}$ & 28.3 & $1.33, \mathrm{~m}$ & 123.9 & $5.40, \mathrm{dtt}(10.7,7.0,1.5)$ \\
\hline $4^{\prime}$ & 22.5 & $1.33, \mathrm{~m}$ & 134.8 & $5.54, \mathrm{dtt}(10.7,7.3,1.5)$ \\
\hline $5^{\prime}$ & 14.1 & $0.90, \mathrm{t}(6.8)$ & 20.8 & $2.10, \mathrm{~m}$ \\
\hline $6^{\prime}$ & & & 14.4 & $0.97, \mathrm{t}(7.5)$ \\
\hline $4-\mathrm{OH}$ & & 5.83 , brs & & 5.89 , brs \\
\hline 3-OMe & 56.1 & $3.93, \mathrm{~s}$ & 56.6 & $3.94, \mathrm{~s}$ \\
\hline 5-OMe & & & 56.6 & $3.94, \mathrm{~s}$ \\
\hline
\end{tabular}

The four known compounds were identified to be methyl (Z)-ferulic acid ester (3) [24], $n$-butyl $(E)$-ferulic acid ester (4) [25], $n$-propyl (E)-ferulic acid ester (5) [25] and methyl (E)-ferulic acid ester (6) [25] by spectroscopic methods and comparison of NMR data with those of formerly reported compounds. All these aromatic constituents were screened for their antioxidant effect in the DPPH radical removing assay and NO release inhibitory activity in a lipopolysaccharide (LPS)-induced murine RAW264.7 macrophage model. While no tested compounds showed obvious NO production inhibitory activity, the two $(Z)$-ferulic acid esters $\mathbf{1}$ and $\mathbf{3}$ did exhibit significant antiradical effect with $\mathrm{IC}_{50}$ of $25.0 \pm 0.7$ and $21.6 \pm 0.9 \mu \mathrm{M}$, respectively, being comparable to that $\left(\mathrm{IC}_{50}=25.4 \pm 2.9 \mu \mathrm{M}\right)$ of the reference compound ascorbic acid.

\section{Acknowledgments}

For the present work, we acknowledge the funding support from Natural Science Foundation [Nos. ZR2018ZC0944, JQ201721] and the Taishan Scholar Project [No. tsqn20161037] of Shandong Province, Jinan Science \& Technology Bureau (No. 2018GXRC003) and the Project of Iceland research center from University of Jinan (18GB04).

\section{Supporting Information}

Supporting information accompanies this paper on http://www.acgpubs.org/journal/records-ofnatural-products

\section{ORCID}

Xin-Xin Cao: 0000-0001-8362-4473

Jin-Yue Sun: $\underline{0000-0002-7377-0319}$ 
Chao Liu: 0000-0003-2680-1810

Jun-Sheng Zhang: 0000-0001-6626-1842

Hua Zhang: 0000-0002-5959-6473

\section{References}

[1] Z. Fu, Y. Liu and Q. Zhang (2016). A potent pharmacological mushroom: Pleurotus eryngii, Fungal Genom. Biol. 6 (1), 139 (5 pages).

[2] A.M. Mariga, W Yang, D.K. Mugambi, F. Pei, L. Zhao, Y. Shao and Q. Hu (2014). Antiproliferative and immunostimulatory activity of a protein from Pleurotus eryngii, J. Sci. Food Agric. 94, 3152-3162.

[3] B. Yuan, L. Zhao, K. Rakariyatham, Y. Han, Z. Gao, B.M. Kimatu, Q. Hu and H. Xiao (2017). Isolation of a novel bioactive protein from an edible mushroom Pleurotus eryngii and its anti-inflammatory potential, Food Funct. 8, 2175-2183.

[4] B. Zhang, Y. Li, F. Zhang, R.J. Linhardt, G. Zeng and A. Zhang (2020). Extraction, structure and bioactivities of the polysaccharides from Pleurotus eryngii: a review, Int. J. Biol. Macromol. 150, 13421347.

[5] T. Kikuchi, M. Isobe, S. Uno, Y. In, T. Yamada, J. Zhang and T. Yamada (2019). Strophasterol E and F: rearranged ergostane-type sterols from Pleurotus eryngii, Bioorg. Chem. 89, 103011

[6] T. Kikuchi, N. Motoyashiki, T. Yamada, K. Shibatani, K. Ninomiya, T. Morikawa and R. Tanaka (2017). Ergostane-type sterols from king trumpet mushroom (Pleurotus eryngii) and their inhibitory effects on aromatase, Int. J. Mol. Sci. 18, 2479.

[7] T. Kikuchi, Y. Horii, Y. Maekawa, Y. Masumoto, Y. In, K. Tomoo, H. Sato, A. Yamano, T. Yamada and R. Tanaka (2017). Pleurocins A and B: Unusual 11(9-7)-abeo-ergostanes and eringiacetal B: a 13,14-seco13,14-epoxyergostane from fruiting bodies of Pleurotus eryngii and their inhibitory effects on nitric oxide production, J. Org. Chem. 82, 10611-10616.

[8] T. Kikuchi, Y. Maekawa, A. Tomio, Y. Masumoto, T. Yamamoto, Y. In, T. Yamada and R. Tanaka (2016). Six new ergostane-type steroids from king trumpet mushroom (Pleurotus eryngii) and their inhibitory effects on nitric oxide production, Steroids 115, 9-17.

[9] T. Kikuchi, Y. Masumoto, Y. In, K. Tomoo, T. Yamada and R. Tanaka (2015). Eringiacetal A, 5,6-seco-(5S,6R,7R,9S)-5,6:5,7:6,9-triepoxyergosta-8(14),22-diene-3 $\beta, 7 \beta$-diol, an unusual ergostane sterol from the fruiting bodies of Pleurotus eryngii, Eur. J. Org. Chem. 4645-4649.

[10] C.X. Zou, Y.Y. Zhang, M. Bai, X.X. Huang, X.B. Wang and S.J. Song (2020). Aromatic compounds from the sclerotia of Inonotus obliquus, Nat. Prod. Res. 1-4. Doi:10.1080/14786419.2019.1677656

[11] Q. Hu, B. Yuan, H. Xiao, L. Zhao, X. Wu, K. Rakariyatham, L. Zhong, Y. Han, B. M. Kimatu and W. Yang (2018). Polyphenols-rich extract from Pleurotus eryngii with growth inhibitory of HCT116 colon cancer cells and anti-inflammatory function in RAW264.7 cells, Food. Funct. 9, 1601-1611.

[12] T. Tanaka, H. Onuma, T. Shigihara, E. Kimura, Y. Fukuta, N. Shirasaka, T. Moriyama and Y. Homma (2019). Anti-osteoporotic effects of syringic acid and vanilic acid in the extracts of waste beds after mushroom cultivation, J. Biosci. Bioeng. 128, 622-629.

[13] S. Liu, Y. Dong, Y. Li, L. Bao, H. Liu and H. Li (2013). Chemical constituents from the rice fermented with the edible mushroom Pleurotus eryngii and their quinone oxidoreductase 1 inducing effect, Fitoterapia 91, 9-14.

[14] M. Gąsecka, M. Mleczek, M. Siwulski and P. Niedzielski (2015). Phenolic composition and antioxidant properties of Pleurotus ostreatus and Pleurotus eryngii enriched with selenium and zinc, Eur. Food. Res. Technol. 242, 723-732.

[15] J.T. Lin, C.W. Liu, Y.C. Chen, C.C. Hu, L.D. Juang, C.C. Shiesh and D.J. Yang (2014). Chemical composition, antioxidant and anti-inflammatory properties for ethanolic extracts from Pleurotus eryngii fruiting bodies harvested at different time, Lwt-Food. Sci. Technol. 55, 374-382.

[16] Z. Xue, J. Li, A. Cheng, W. Yu, Z. Zhang, X. Kou and F. Zhou (2015). Structure identification of triterpene from the mushroom Pleurotus eryngii with inhibitory effects against breast cancer, Plant Food Hum. Nutr. 70, 291-296.

[17] S.J Wang, Y.X Li, L. Bao, J.J Han, X.L Yang, H.R. Li, Y.Q. Wang, S.J. Li and H.W. Liu (2012). Eryngiolide A, a cytotoxic macrocyclic diterpenoid with an unusual cyclododecane core skeleton produced by the edible mushroom Pleurotus eryngii, Org. Lett. 14, 3672-3675.

[18] T. Kikuchi, K. Kitaura, A. Katsumoto, J. Zhang, T. Yamada and R. Tanaka (2018). Three bisabolane-type sesquiterpenes from edible mushroom Pleurotus eryngii, Fitoterapia 129, 108-113. 
[19] L.Y. Liu, Z.H. Li and J.K. Liu (2013). A new menthane-type monoterpene from Pleurotus Eryngii, Chin. J. Nat. Med. 11, 71-73.

[20] P. Wang, J.H. Yu, K. Zhu, Y. Wang, Z.Q. Cheng, C.S. Jiang, J.G. Dai, J. Wu and H. Zhang (2018). Phenolic bisabolane sesquiterpenoids from a Thai mangrove endophytic fungus, Aspergillus sp. xy02, Fitoterapia 127, 322-327.

[21] A. Baran, Emel Karakılıç, Ö. Faiz and F. Özen (2020). Synthesis of chalcone-containing zinc and cobalt metallophthalocyanines; investigation of their photochemical, DPPH radical scavenging and metal chelating characters, Org. Commun. 13(2), 65-78.

[22] H. T. Aung, M. M. Aye, Z. M. Thu, Y. Komori, M. M. Sein, G. Vidari and Y. Takaya (2020). Bioactive constituents from the rhizomes of Sansevieria cylindrica, Rec. Nat. Prod. 14(4);269- 27.

[23] J.S. Zhang, X.X. Cao, J.H. Yu, Z.P. Yu and H. Zhang (2020). Diarylheptanoids with NO production inhibitory activity from Amomum kravanh, Bioorg. Med. Chem. Lett. 30, 127026.

[24] W. Wang, J. Guo, J. Zhang, J. Peng, T. Liu and Z. Xin (2015). Isolation, identification and antioxidant activity of bound phenolic compounds present in rice bran, Food Chem. 171, 40-49.

[25] N.G. Li, Z.H. Shi. Y.P. Tang, B.Q. Li and J.A. Duan (2009). Highly efficient esterification of ferulic acid under microwave irradiation, Molecules 14, 2118-2126.

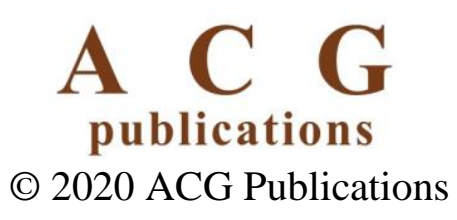

